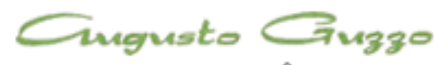

REVISTA ACADÉMICA

\title{
Língua dos ciganos - Clã dos Cesteiros
}

\author{
Álvaro Fernando Rodrigues da Cunha' \\ Recebido em: 03/10/2014. Aprovado em: 14/11/2014. Disponibilizado em: 26/12/2014
}

1. Álvaro Fernando Rodrigues da Cunha é pós-doutor em Etno-antropo-linguística. Atual cientista Pesquisador e professor da Aliant International University - Universidade San Diego - Califórnia. Doutor em Língua Portuguesa. USP, 2010. Mestre em Língua Portuguesa. USP, 2008. Graduado em Letras. Universidade da Amazônia, 2002. Domina fluentemente Inglês, espanhol, e grego. De 2012 a 2013 foi Cientista da Unicamp na criação da TeCOE® -Teoria de Cruzamento em Oralidade e Escrituralidade - Unicamp. E pesquisador no Laboratório de Estudos sobre Etnicidade, Racismo e Discriminação - LEER-USP. Publicou três livros sobre Etno-antropo-linguista nas tribos indígenas. Email: afrdac@gmail.com.

\section{Resumo}

Existe uma curiosidade quando se fala em língua cigana ou língua dos Kalõs, uma civilização milenar, que não falam um idioma único, pois, espalhados pelo mundo, o mesmo povo fala em várias línguas.E, a depender da comunidade, no que diz respeito ao aspecto linguístico, uma muda potencialmente de outra que pode, inclusive, ter os seus membros morando no mesmo arraial, por exemplo. No caso da pesquisa, a descrição que se verá no desenrolar da investigação foi totalmente estribada no clã dos ciganos fixados temporariamente no município de Arthur Nogueira, SP. Não disseram de onde vieram nem para aonde seguirão. Nem eles sabem por quanto tempo ficarão residindo nesse município, pois são nômades urbanos, isto é, não se fixam em lugar nenhum, e basta amanhecerem com a vontade de se mudarem daquele lugar para que isso se torne realidade. São instáveis e não se apegam a nada. Foi aproveitada a permanência deles no município supramencionado para se fazer o levantamento de dados a respeito da língua que falam.

Palavras-chave: Kalõs ou língua do clã dos ciganos, aspecto linguístico do povo cigano, nômades urbanos.

\begin{abstract}
There is a curiosity when it comes to Romany language or language of the Kalõs, an ancient civilization who do not speak a single language, by the way, around the world the same people speak in different languages. Depending on the community with regard to the linguistic aspect, a change of other potentially that may even have its members living in the same camp for example. In this research the description that we will see in course of investigation, was fully anchored in the clan of gypsies set temporarily in the municipality of Arthur Nogueira, SP. They did not say where they came from or where to follow. Nor do they know how long will residing in this city, as are urban nomads, namely not fixed anywhere, and just dawn with the desire to move from that place to make it a reality. They are unstable and they don't cling to anything. Their stay in the aforesaid county to do the survey data about the language they speak.
\end{abstract}

Keywords: Kalos or clan language of the Gypsies, linguistic aspect of Romany, urban nomad. 


\section{Introdução}

Quando se fala em língua dos Kalõs ou língua cigana há certa curiosidade em relação a esse povo milenar. Principalmente porque eles não falam um idioma único, ou seja, são várias línguas no mundo para um povo. $\mathrm{E}$, a depender da comunidade, no que diz respeito ao aspecto linguístico, uma muda potencialmente de outra que pode, inclusive, ter os seus membros morando no mesmo arraial, por exemplo. No caso da pesquisa que se fez, a descrição que se verá abaixo foi totalmente estribada no clã dos ciganos que mora(va)m no município de Arthur Nogueira, SP. Não nos disseram de onde vieram nem para aonde vão; não sabemos por quanto tempo ficarão residindo nesse município, pois são nômades urbanos, isto é, não se fixam em lugar nenhum, e basta amanhecerem com a vontade de se mudarem daquele lugar para que isso se torne realidade. São instáveis e não se apegam a nada. Aproveitamos a permanência deles no município supramencionado para fazer o levantamento de dados a respeito da língua que falam.

Foram gentis e nos receberam com alegria e o sorriso estampado no rosto, característica, aliás, bem típica do povo cigano. Não diremos que tudo correu bem do início ao fim da pesquisa, porque houve, nalgum momento da coleta de dados, dois ou três ciganos enfurecidos pelo fato de estarmos "roubando" a língua kalõ, porém o restante do grupo foi, a nosso favor e nada de grave aconteceu. Passamos meses na coleta dos dados linguísticos, vivenciando o cotidiano desse povo.

Resistentes ou não à questão da escrita no idioma que são proficientes, o que importa é a documentação e descrição desse único falar, inédito, na linguística descritiva. Por razão de eles serem ágrafos, é bem provável que seja relativamente impossível definir sua verdadeira origem.

Assim, o que se fala a respeito das origens dos ciganos está largamente baseado em hipóteses, analogias e opiniões que não se fundam em provas positivas, mas em meras conjeturas.

Dizem que os ciganos vieram da Índia, aproximadamente dois ou três milênios antes de Cristo, donde foram expulsos por invasores árabes. Após a diáspora oriental, os ciganos invadiram o Ocidente e espalharamse pelo resto do mundo. Tal "invasão" foi uma das únicas, na história do homem, feita sem derramamento de sangue, dor ou guerra.

Os ciganos são insignes vendedores, comerciantes de varejo e leitores da sorte (quiromancia). Viajam sempre em grupos e criam para si próprios nomes poéticos a fim de nomearem seus grupos.

Com eles, vêm no bojo a música, a dança, as palmas e as batidas dos pés. Não aceitam serem empregados de não ciganos, porque se sentem superiores desde sua origem. Os ciganos têm como lema "O céu é meu teto; a Terra, minha pátria e a liberdade, minha religião". Um espírito nômade cuja vida é uma grande estrada, onde a alma é uma pequena carroça e a divindade é o carroceiro. São rotulados de mentirosos, ladrões, feiticeiros e vagabundos.

Cantam e dançam, tanto na alegria quanto na tristeza, porque para o cigano "mundolaxõ" - a vida é bela -; "nossa existência é uma festa e a natureza que nos rodeia é a mais bela e generosa anfitriã". Onde estiverem, são logo reconhecidos pelas roupas que usam e seus ornamentos nada discretos.

\section{Descrição articulatória dos sons e sua distribuição}


A compreensão da formação da fonologia do Kalõ dos ciganos em Arthur Nogueira SP deve partir do conhecimento do estado atual da língua, o mais aproximado possível. Abaixo, segue o quadro das realizações fonéticas que existem na fala deste grupo supramencionado.

2.1. Quadro fonético dos segmentos consonantais

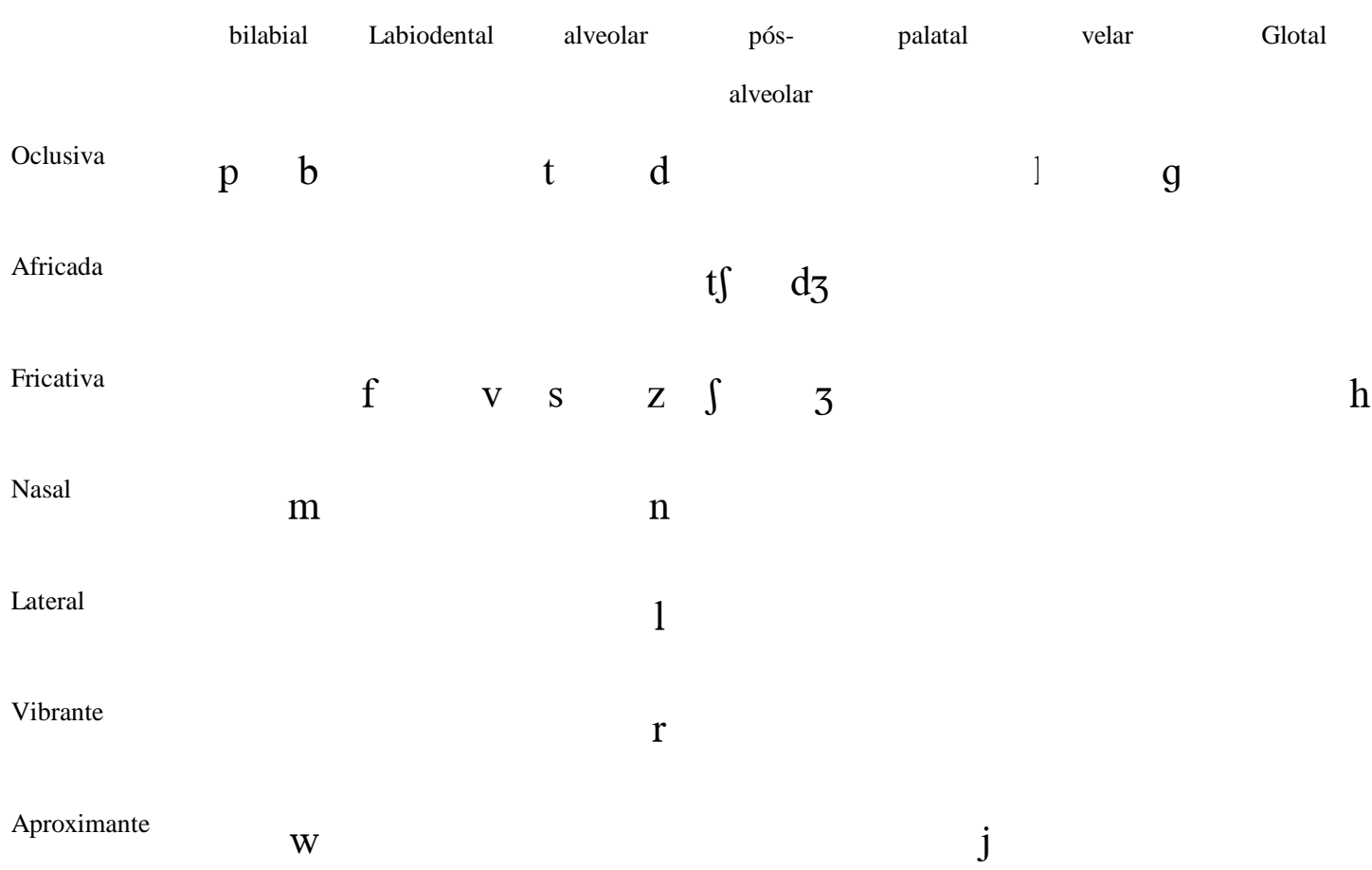

2.2. Consoantes oclusivas

[p] oclusiva bilabial surda:

[\#_V]

[pa.'hã] 'pau'

[pe.'hõ] 'pé'

[pĩ.'ah] 'beber'

['po.ka] 'barro' 
[pu.'3i.la] 'tomate'

$\left[\mathrm{V} \_\mathrm{V}\right]$

[a.ve.la.pu.'a.gi] 'fogo'

[a.Se.la.dzi.pe.'rah] 'levantar'

[ka.tro.'pe.a] 'quadrúpede’

[b] oclusiva bilabial sonora:

[\#_V]

['baj.li] 'cabelo'

[be.'rõ] 'carro'

['bi.da] 'carteira'

['bo.fi] 'fome'

['bu.li] 'nádegas'

[V_V]

[a.ba.luh.'nĩ] 'barraca'

[ef.ta.ri.'bĩ] 'cama'

[ba.ba.'nõ] 'bonito' 
[t] oclusiva alveolar surda:

[\#_V]

[ta.'rõ] 'teu'

['te.bis] 'mesa'

[t fi.ka.'me.lu] 'amar'

[to.'ne.ru] 'branco'

[tu.'rã.gi] 'o que não tem valor'

$\left[\mathrm{V} \_\mathrm{V}\right]$

[es.pe.'te.ra] 'manchado'

[he.'ta.ku] 'tosse'

[ba.'tã] 'noivo'

[d] oclusiva alveolar sonora:

[\#_V]

[daj] 'mãe'

[de.ha.'mõ] 'espírito mau'

[d3i.kĩ.'ah] 'ver'

[dõ] 'estrada'

[du.'ve.li] 'Jesus' ou 'Deus' 


\section{$\left[\mathrm{V} \_\mathrm{V}\right]$}

[ma.de.'ah] 'agitar o leite'

[ke.'dah] 'perder'

[te.'ri.da] 'fazenda'

[k] oclusiva velar surda:

[\#_V]

[ka.'lõ] 'cigano'

['ke.ri] 'casa'

[ki.lî.'dah] 'dançar'

['kõ.bri] 'sal'

[ku.hu.'pi.fi] 'arroz'

\section{$\left[\mathrm{V} \_\mathrm{V}\right]$}

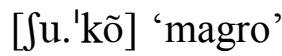

[pa.'kĩ] 'banana'

[if.tfi.'la.ki] 'sapato'

[g] oclusiva velar sonora:

$\left[\# \_\mathrm{V}\right]$ 
['ga.dzi] 'camisa'

['ge.la] 'cinco'

['gi.nu] 'dor'

[go.'mi.zu] 'amanhã'

[gu'.lõ] 'açúcar'

$\left[\mathrm{V} \_\mathrm{V}\right]$

[mã.'dẽ.ga] 'mandioca'

['ma.ga] 'comida ruim'

[sa.'gu.li] 'cego'

2.3. Consoantes fricativas

[f] fricativa labiodental surda:

[\#_V]

['fa.gu] 'roda'

[fej.'zo.li] 'feijão'

[fis.'ka.li] 'cigarro'

['fo.ba] 'empréstimo'

['fu.su] 'bebida quente' 
[V_V]

['sa.fi] 'puro'

['le.fa] 'coisa pegajosa'

['ka.fis] 'impaciência'

[v] fricativa labiodental sonora:

[\#_V]

[vajs] 'mão'

['ve.zi] 'duro'

[vi.'sa.to] 'tinta'

[vo.'ke.ta] 'armário'

[vu.'do.zi] 'meia'

$\left[\mathrm{V} \_\mathrm{V}\right]$

[gru.'vĩ] 'vaca'

[ba.li.'vas] 'óleo de cozinha'

[su.vĩ.'ah] 'sonho'

[s] fricativa alveolar surda:

$\left[\# \_\mathrm{V}\right]$ 
[sa.ve.'3ah] 'levar'

['sa.du] 'parente'

[si.'mẽ.ni] 'paz'

['so.t $\mathrm{i}$ i] 'chuva'

[su.na.'kaj] 'ouro'

$\left[\mathrm{V} \_\mathrm{V}\right]$

[tra.sa.'li.t5i] 'cedo'

[ta.sa.'dah] 'brigar'

[mi.'su.la] 'beira'

[z] fricativa alveolar sonora:

[\#_V]

[za.la.'kẽ] 'olho'

['ze.nu] 'depois'

[zi.'rah] 'nascer'

['zo.t5i] 'lixo'

['zu.ja] 'conversa'

$\left[\mathrm{V} \_\mathrm{V}\right]$ 
[ba.'zi.ra] 'conta'

[bra.'ze.ru] 'brasileiro'

[ma.'ze.bi] 'cântaro'

[S] fricativa pós-alveolar surda:

[\#_V]

[ [a.bu.'hõ] 'menino'

[Se.'rõ] 'cabeça'

[Si.'de.pu] 'viagem'

[So.'tfi.si] 'vergonha'

['Su.tSi] 'leite'

$\left[\mathrm{V} \_\mathrm{V}\right]$

[dzi.'mẽ.fa] 'nosso'

['tũ.Ja] 'tu'

[ba.li.'Sõ] 'porco'

[3] fricativa pós-alveolar sonora:

[\#_V]

[3u.ga.'lõ] 'feio' 


\author{
['ze.li] 'papagaio' \\ [3i.'na.rju] 'polícia' \\ [3o.'go.va] 'cebola' \\ [3u.'ke.li] 'cachorro'
}

\title{
$\left[\mathrm{V} \_\mathrm{V}\right]$
}

[na.'3i.la] 'ira'

[le.'3ĩ] 'mariposa'

['do.za] 'oferta'

[h] fricativa glotal surda:

[\#_V]

[haj.'ah] 'comer'

[he.mĩ.dzi.'ah] 'casar'

['hi.ga] 'planta'

[hõ] 'homem'

[hu.'pi.ri] 'saia'

\section{$\left[\mathrm{V} \_\mathrm{V}\right]$}

[pa.'hu.da] 'trocar' 
['ha.da] 'merda'

[le.'ha.fi] 'seda'

2.4. Consoantes nasais

[m] nasal bilabial:

[\#_V]

[mah.'dah] 'matar'

['me.la] 'meu'

[mi.rĩ.'ah] 'morrer'

[mo.'li.du] 'zombador'

[mũ.du.la.'Sõ] 'viver'

$\left[\mathrm{V} \_\mathrm{V}\right]$

[nu.'mo.la] 'chato'

[pe.'ma.zu] 'coisa muito apertada'

['sa.ma] 'servente'

[n] nasal alveolar:

[\#_V]

[na. $\int \tilde{1}$. 'ah] 'correr'

['ne.ka] 'não' 
[ni.'no.tfi] 'batizado'

['no.va] 'sábio'

[nu.'ge.li] 'lona'

$\left[\mathrm{V} \_\mathrm{V}\right]$

[kã.dzi.'pã.nu] 'fedido'

['dã.ni] 'dente'

[bi.'nah] 'vender'

2.5. Consoante lateral

[1] lateral alveolar:

[\#_V]

[la.' 'õ] 'gostoso'

[le.'tã] 'palheiro'

[li.'ka.t $\left.\int i\right]$ 'espelho'

['lo.dzi] 'doido'

[lu.'si.va] 'magia'

$\left[\mathrm{V} \_\mathrm{V}\right]$

[dzi.'a.li] 'verdade' 
[ku.'le.bra] 'cobra'

[ $\int u$ u.'lõ] 'gordo'

\section{QUADRO FONÉTICO DOS SEGMENTOS VOCÁLICOS ORAIS}

anteriores não-arreds. central não-arred. $\quad$ posteriores arreds.
Alta
i
u
Méd.-Alta
e
o
Baixa
a

\subsection{Vogais anteriores}

[i] anterior não-arredondada alta oral:

[\#__]

[is.'ta.dzi] 'chapeu'

[is.tu.'re.la] 'fita'

[i.de.'rã] 'gargantilha'

[C_C $]$

[3ũ.di.'na.rju] 'o que não é cigano'

[pi.'1õ] 'tomar bebida'

[gwa.'ri.na] 'calsa' 
[_\#]

[Su.'`ã.ni] 'seio'

['kwe.ri] 'incenso'

['kã.bri] 'sol'

[e] anterior não-arredondada média-alta oral:

[\#__]

['e.bu] 'catarro'

[e.'ma.la] 'liso'

['es.da] 'conservado'

$\left[\mathrm{C} \_\mathrm{C}\right]$

['zeh.ka] 'laranja'

[3e.le.'ah] 'ferir'

[mes.'to.ra] 'abrigo'

[_\#] Fone em fim de palavra não encontrado.

2.7. Vogal central

[a] central não-arredondada baixa oral: 
[\#_]

[a.ba.luh.'nĩ] 'barraca'

[a.ve.la.pu.'a.gi] 'fogo'

[a.Je.la.dzi.pe.'rah] 'levantar'

[C_C $]$

[ha.'dẽs] 'dinheiro’

[da.'rõ] 'homem bravo'

[kah.'dõ] 'preto'

[_\#]

['mẽ.fa] 'eu'

['nus.ka] 'nós'

['ne.ka] 'não'

2.8. Vogais posteriores

$[\mathrm{u}]$ posterior arredondada alta oral:

[\#_]

[u.'ra.tfi] 'vermelho'

['uh.ta] 'tabaco em pó' 
[u.'za.ri] 'orfã'

$\left[\mathrm{C} \_\mathrm{C}\right]$

[puf.'tã] 'lençol'

[bu.'da.ri] 'porta'

[nu.'võ] 'novo'

[_\#]

[pah.'ta.lu] 'couro'

[pe.'ma.zu] 'coisa muito apertada'

[ i.'de.pu] 'viagem'

[o] posterior arredondada média-alta oral:

[\#__]

[o.'ra.tfi] 'sangue'

[o.be.'30̃] 'abelha'

['o.fa] 'mulher parida'

$\left[\mathrm{C} \_\mathrm{C}\right]$

['zo.tsi] 'lixo' 
['fo.ba] 'empréstimo'

['po.ka] 'barro'

[_\#] Fone em fim de palavra não encontrado.

\section{QUADRO FONÉTICO DOS SEGMENTOS VOCÁLICOS NASALIZADOS}

anteriores não-arreds. central não-arred. posteriores arreds.
Alta
$\tilde{1}$
$\tilde{\mathrm{u}}$
Méd.-Alta
$\tilde{\mathrm{e}}$
$\tilde{0}$

Baixa

$\tilde{a}$

2.9. Vogais anteriores

[ĩ] anterior não-arredondada alta nasalizada:

[\#_]

[ĩ.'ka.la] 'farinha mal moída'

[ĩs.'te.ku] 'apelido'

$\left[\mathrm{C} \_\mathrm{C}\right]$

[ki.lî.'dah] 'dançar'

[he.mĩ.dzi.'ah] 'casar' 
[_\#]

[pa.'ĩ] 'água'

[kah.'nĩ] 'mulher brava'

[ẽ] anterior não-arredondada média-alta nasalizada:

[\#__]

[ẽ.'ka.va] 'viúvo'

[ẽ.'sẽ] 'pedra de amolar faca'

$\left[\mathrm{C} \_\mathrm{C}\right]$

[si.'mẽ.ni] 'paz'

[mã.'dẽ.ga] 'mandioca'

[_\#]

[pja.'pẽ] 'remédio'

[ẽ.'dẽ] 'onde'

2.10. Vogal central

[ã] central não-arredondada baixa nasalizada:

[\#__] 
[ã.'dra.ki] 'colchão de cama'

[ã.'si.na] 'antigo'

$\left[\mathrm{C} \_\mathrm{C}\right]$

[mã.'dẽ.ga] 'mandioca'

[tu.'rã.gi] 'o que não tem valor’

[_\#]

[le.'tã] 'palheiro'

[pa.'hã] 'pau'

2.11. Vogais posteriores

[ũ] posterior arredondada alta nasalizada:

[\#_]

['ũ.ba] 'nação'

[ũ.dre.'ar] 'esticar'

[C_C]

[3ũ.di.'na.rju] 'o que não é cigano'

[hũ.'si.la] 'formiga' 
[_\#]

[drũ] 'nome próprio'

[ka.'sũ] 'o melhor'

[õ] posterior arredondada média-alta nasalizada:

[\#__]

[õ.'rõ] 'ovo'

[õ.'ho.ru] 'riacho'

[C_C $]$

['kõ.bri] 'sal'

[za.'rõ.ka] 'dente de ouro'

[_\#]

[ma.'rõ $] \mathrm{meu}$

[ e.'rõ] 'cabeça'

\section{Fonologia Segmental}

Abaixo, a análise dos fonemas consonantais e vocálicos, verificando a distribuição.

3.1. Distribuição complementar dos segmentos consonantais

Os segmentos abaixo estão em distribuição complementar e, portanto, devem ser considerados alofones dum mesmo fonema, ei-los: 
$\mathrm{O}$ fonema / $\mathrm{t} /$ realiza-se com o alofone $\left[\mathrm{t} \int\right]$, diante de /i/ e com [t], nos demais casos.

Exemplos:

$\begin{array}{lll}\text { [ta.'rõ] } & / \text { ta'roN/ 'teu'; } \\ \text { ['te.bis] } & / \text { 'tebes/ 'mesa'; } \\ \text { [tfi.ka.'me.lu] } & / \text { tika'melo/ 'amar'; } \\ \text { [to.'ne.ru] } & / \text { to'nero/ 'branco'; e } \\ \text { [tu.'rã.gi }] & \text { /tu'raNge/ 'o que não tem valor'. }\end{array}$

O fonema /d/ realiza-se com o alofone [d] , diante de /i/ e com [d], nos demais casos.

Exemplos:

[daj] /daj/ 'mãe';

[de.ha.'mõ] /deha'moN/ 'espírito mau';

[dzi.kĩ.'ah] /dikiN'ah/ 'ver';

[dõ] /doN/ 'estrada'; e

[du.'ve.li] /du'vele/ 'Jesus' ou 'Deus'.

Não foi constatado nenhum caso de variação livre na língua. 


\section{FONEMAS CONSONANTAIS}

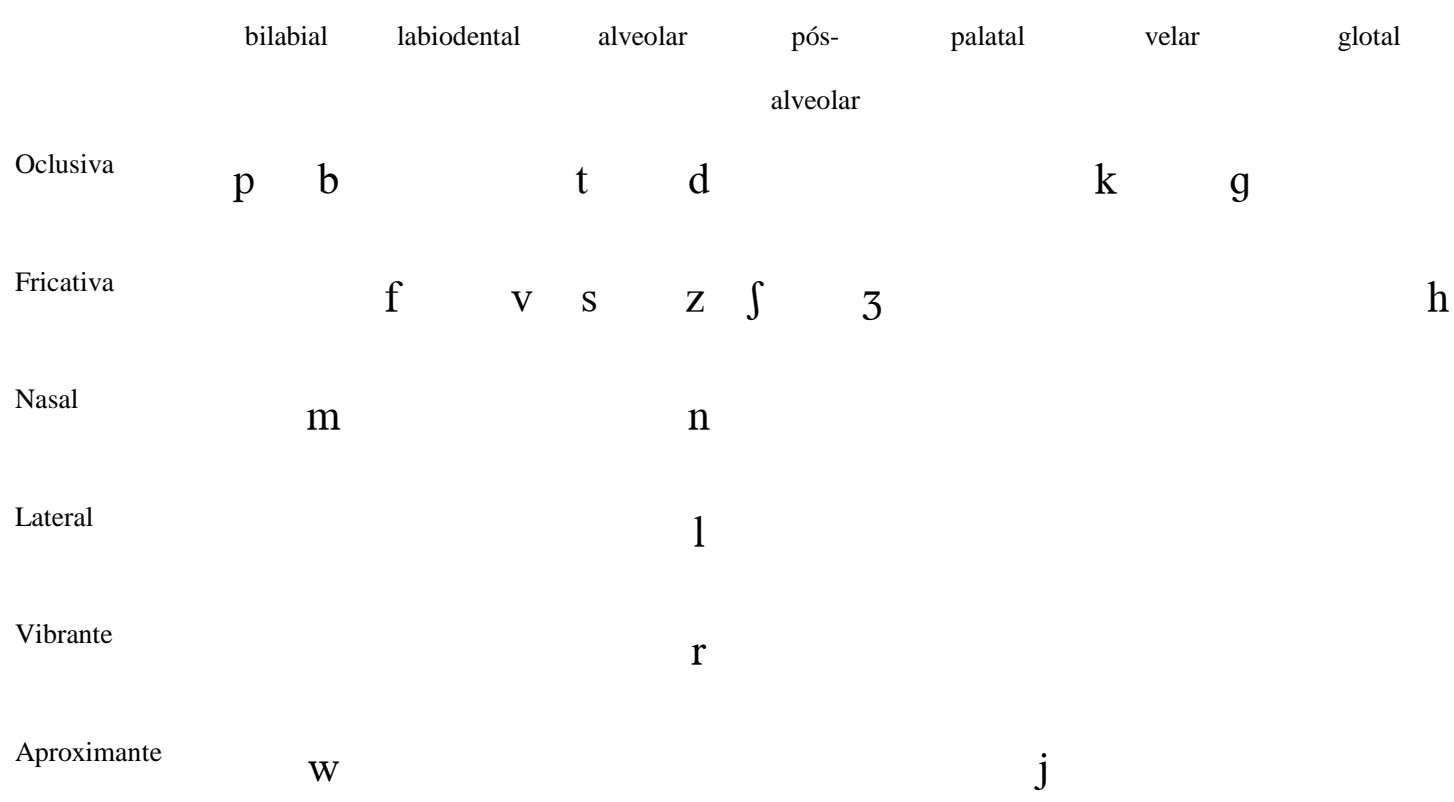

A seguir, a fonologia dos segmentos vocálicos. Observaremos a oposição entre vogais orais.

4. Oposição entre fonemas vocálicos orais

Devem ser considerados fonemas distintos os segmentos vocálicos orais que estão em oposição:
$/ \mathrm{a} /: / \mathrm{e} /$
/a'bede/
[a.'be.dzi]
'tintura de cabelo'
/e'bede/
[e.'be.dzi] 'solteiro'
/i/ : /e/
/i'faza/
[i.'fa.za] 'mania'
/e'faza/
[e.'fa.za] 'altura'
$/ \mathrm{u} /: / \mathrm{o} /$
/u'rate/
[u.'ra.tsi] 'vermelho'
/o'rate/
[o.'ra.tsi] 'sangue' 


\section{FONEMAS VOCÁLICOS ORAIS}

anteriores não-arreds. $\quad$ central não-arred. $\quad$ posteriores arreds.

Alta

Méd.-Alta

Baixa

5. O molde silábico i

$\mathrm{e}$ $\mathrm{u}$

o

a

Observando a estrutura silábica do Kalõ é possível verificar as seguintes combinações, onde C em VC pode ser uma fricativa ou uma nasal, o segundo C em CCV só pode ser uma vibrante; porque se ocorresse, por exemplo, outra consoante diferente da supramencionada haveria fatalmente uma juntura aberta, o que foneticamente corresponderia a um resquício vocálico entre C e C, assim: *bs. 'go.la >> bis. 'go.la.

1. V

/di'ale/

'verdade';

2. VC

/'esda/

'conservado';

3. $\mathrm{CV}$

/'kere/

'casa';

4. CCV /bra'zero/ 'brasileiro';

5. CVC

/'zehka/

'laranja'; e

6. CVCC

/majs/

'carne'. 
E pode ser assim representado em forma de árvore:

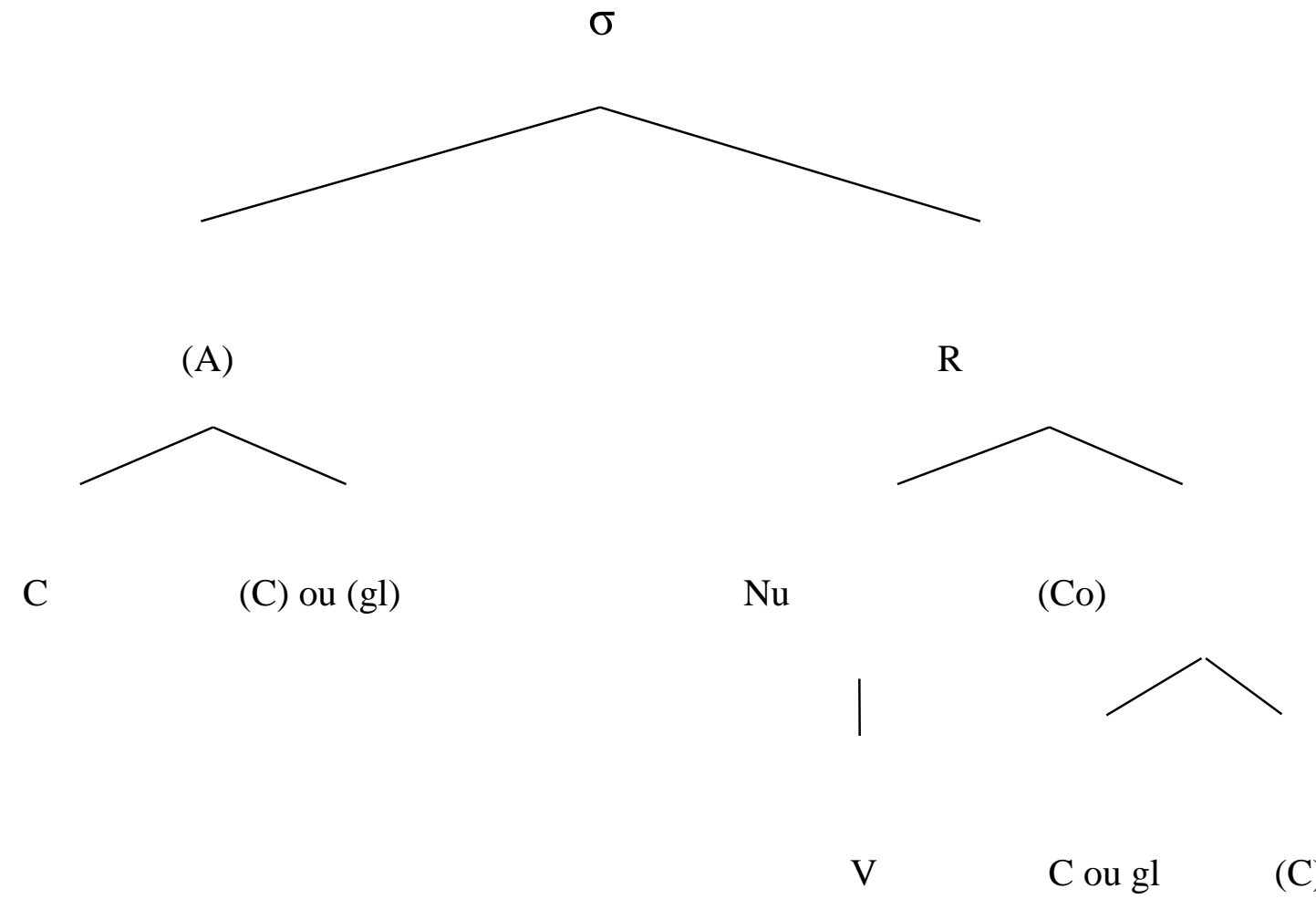


6. Ataque silábico

Na posição de Ataque silábico temos o seguinte cânone:

A

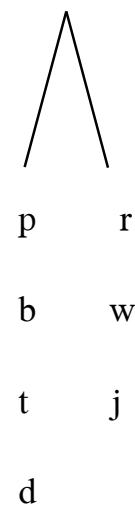

$\mathrm{k}$

g

f

$\mathrm{V}$

S

Z

$\int$

3

$\mathrm{h}$

$\mathrm{m}$

$\mathrm{n}$

1 


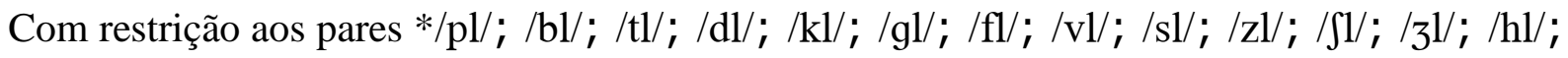
$/ \mathrm{ml} / ; / \mathrm{nl} / ; / 11 / ; / \mathrm{jl} / ; / \mathrm{wl} / ; / \mathrm{rl} / ; / \mathrm{vr} / ; / \mathrm{sr} / ; / \mathrm{zr} / ; / \mathrm{rr} / ; / 3 \mathrm{r} / ; / \mathrm{hr} / ; / 3 \mathrm{r} / ; / \mathrm{hr} / ; / \mathrm{mr} / ; / \mathrm{nr} / ; / \mathrm{r} / ;$ $/ \mathrm{rr} /$.

O Glide em posição secundária, no Ataque ramificado, aponta a existência do ditongo crescente no Kalõ, por exemplo: /gwa'rina/ 'calça'; /zi'narju/ 'polícia'.

Exemplos de séries permitidas no Ataque ramificado:

1. /bra'zero/ 'brasileiro';

2. /gwa'rina/ 'calça'; e

3. /3i'narju/ 'polícia'.

7. Núcleo silábico

Na posição de Núcleo silábico temos o seguinte cânone:

$$
\begin{aligned}
& \left.\right|_{\mathrm{Nu}} \\
& \mathrm{a} \\
& \mathrm{e} \\
& \mathrm{o} \\
& \mathrm{i} \\
& \mathrm{u}
\end{aligned}
$$


Os exemplos mostram as séries de Núcleo silábico:

1. /'esda/ 'conservado';

2. /ide'raN/ 'gargantilha';

3. /abaluh'niN/ 'barraca';

4. /u'rate/ 'vermelho'; e

5. /o'rate/ 'sangue'.

8. Coda silábica

Na posição de Coda silábica temos o seguinte cânone:

Co

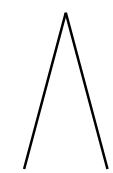

S S

h

$\int$

N

j

1. /'esda/ 'conservado';

2. /tasa'dah/ 'brigar';

3. $/ \mathrm{pu} \int^{\mathrm{l}} \operatorname{taN} /$ 'lençol'; 

4. /abaluh'niN/ 'barraca';
5. /daj/
'mãe'; e
6. /majs/
'carne'.

Pode-se observar que a presença da aproximante /j/ na Coda dá indício da existência de ditongo decrescente no Kalõ; o arquifonema nasal /N/, em Coda silábica, será discutido mais adiante; o fonema /s/ como segundo elemento de Coda ramificada indica a sílaba máxima que o idioma estudado pode atingir.

\section{Agrupamento silábico}

Clements \& Keyser (1983, p. 28) propuseram que as línguas apresentam padrões bem definidos quanto aos agrupamentos silábicos:

a) todas as línguas possuem padrão CV;

b) há línguas que permitem supressão da consoante à esquerda do ápice silábico; e

c) há línguas que permitem consoante à direita do Núcleo silábico.

Assim, propõem a seguinte tipologia para as línguas:

Tipo 1: CV — aceitam somente $a$, portanto, não têm encontros vocálicos ou consonantais heterossilábicos na cadeia da fala;

Tipo 2: CV V — aceitam $a$ e $b$, portanto, não possuem encontros vocálicos heterosilábicos;

Tipo 3: CV CVC — aceitam $a$ e $c$, portanto, não possuem encontros consonantais heterossilábicos; 
Tipo 4: CV V CVC VC - aceitam $a, b$ e $c$, portanto, têm encontros vocálicos e consonantais heterossilábicos.

Tomando-se as palavras /zi'narju/, /di'ali/, /bra'zero/, /majs/ e /'zehka/ é possível verificar que o Kalõ tem encontros vocálicos e consonantais heterossilábicos, portanto, é de tipo 4, isto é, possui o padrão CV e admite a inserção de consoante à direita do Núcleo silábico.

\section{Arquifonema}

As consoantes nasais $/ \mathrm{n} / \mathrm{e} / \mathrm{m} /$, em Coda silábica, neutralizam-se e provocam a representação dum arquifonema nasal /N/. Noutros contextos, observa-se a oposição entre ambas. Contextos:

1. [\#_V]

['me.la] 'meu'

['ne.ka] 'não'

2. [V_V]

['sa.ma] 'servente'

['dã.ni] 'dente'

Mas em Coda silábica, essa oposição desaparece:

3. [V_\#]

[le.'tan]

'palheiro'

e $\quad[$ le.'tam $]$

'palheiro'

[3u.ga.'lon]

'feio'

e [3u.ga.'lom]

'feio'

[3un.di.'na.rju]

'não-cigano'

e [3um.di.'na.rju]

'não-cigano' 
O que nos faz postular a regra:

$/ \mathrm{n} / \mathrm{e} / \mathrm{m} / \longrightarrow / \mathrm{N} / / \ldots \mathrm{Co}$

Os fonemas /n/ e /m/ tornam-se arquifonema nasal /N/ em Coda silábica:

$/ \mathrm{e}^{\mathrm{t}} \mathrm{taN} /$;

/3uga'loN/; e

/zuNdi'narju/.

11. Acento

O Kalõ tem a acentuação muito previsível, onde este sempre cairá na penúltima sílaba (paroxítona), à exceção de palavras cuja última sílaba (oxítona) é nasalizada ou tem a terminação verbal, porém o acento nunca incidirá sobre a antepenúltima sílaba (proparoxítona); assim:

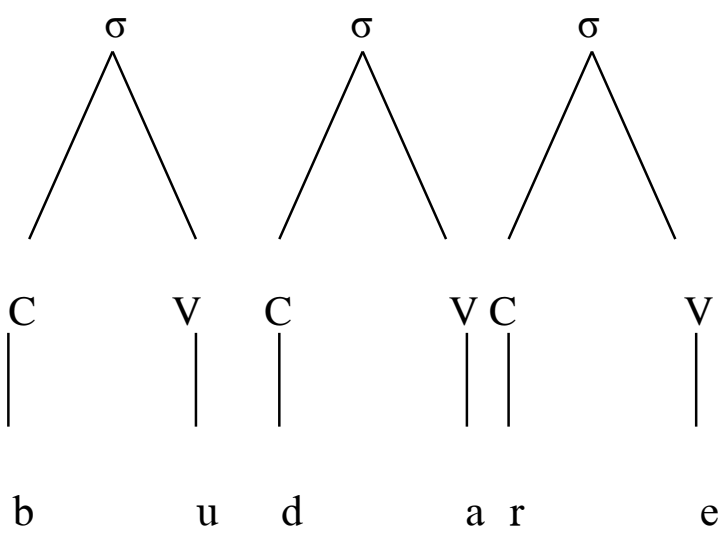



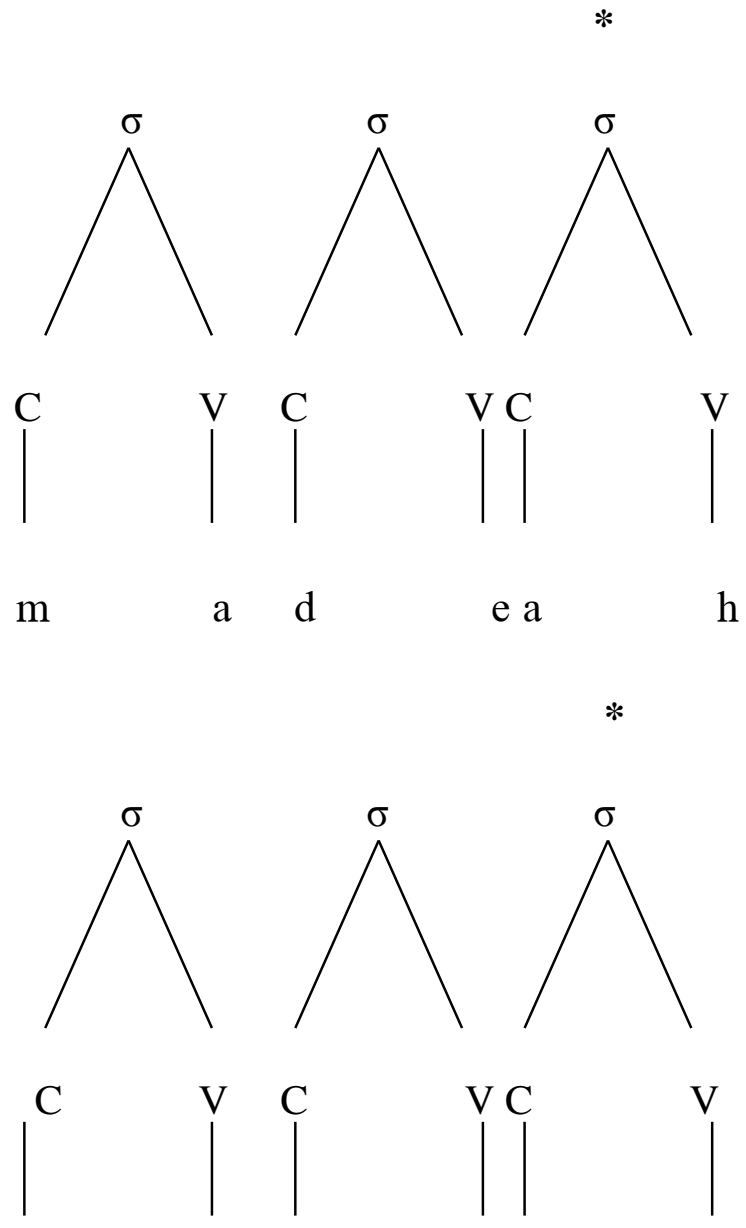

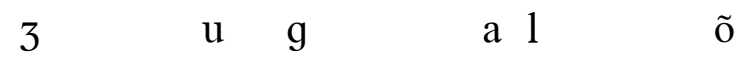

Não houve constatação de exceção à regra de acentuação na língua Kalõ. O sistema, ao que parece, é bem previsível. Seguindo à regra: 


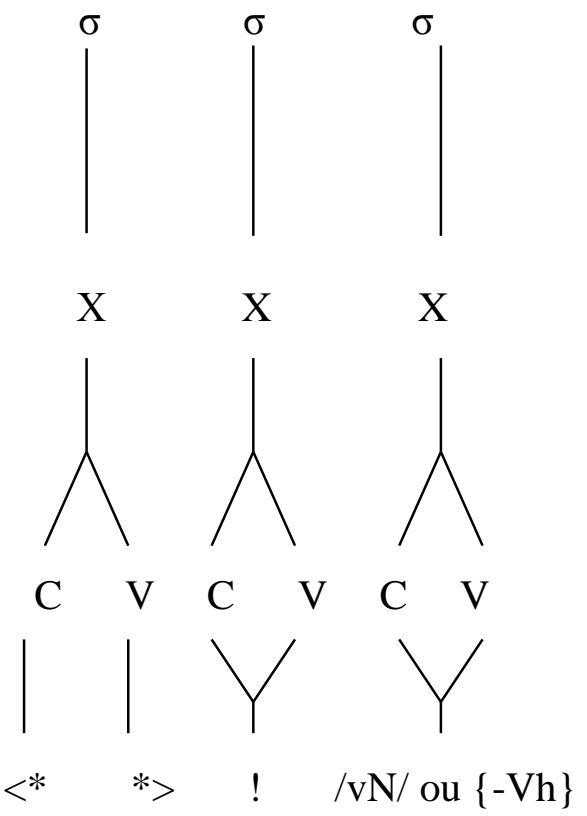

Onde se lê, na última sílaba (oxítona) só ocorrerá acento se essa terminar em vogal nasalizada /vN/ ou na terminação verbal $\{-\mathrm{Vh}\}$; já na penúltima sílaba (paroxítona) o acento é obrigatório, à exceção das duas idiossincrasias supracitadas; e na antepenúltima sílaba (proparoxítona) o acento é extramétrico.

\section{Proposta gráfica}

O kalõ é uma língua de diáspora sem linhas geograficamente definidas, de vínculo cultural com um grupo étnico que mantém suas tradições, costumes e religião cigana. Com o passar do tempo, foi-se adaptando aos países em que adentrou (situação de contato linguístico) e esse contato do Kalõ com o português favoreceu a uma interação linguística entre ambos. O que é natural em se tratando desse tipo de fenômeno. Os ciganos são ágrafos, pelo menos esse grupo que contatamos e documentamos e descrevemos a língua.

Caso comparemos o Kalõ ao Português, que é uma língua com pergaminhos de antiguidade, nobreza e excelência, em que os copistas procuravam soluções gráficas, apesar de 
algumas realidades fônicas mais recentes ainda serem desconhecidas, no Kalõ não há essa preocupação, tanto que eles não têm escrita.

Eis a proposta gráfica para o Kalõ em letras maiúsculas e minúsculas:

1. A e a - Avelapuáge, 'fogo';

2. B e b - Báile, 'cabelo’;

3. D e d _ - Dãi, _mãe'

4. Ee e - Êbo, 'catarro';

5. Fef - Feizôle, 'feijão';

6. G e g - Gáde, 'camisa';

7. I e i _chapeu';

8. J e j _ Jukêle, 'cachorro';

9. Le $1 \quad-\quad$ Laxõ, _'gostoso'; 
10. M e m - Mahdáh, 'matar';

11. N e n - Naxĩáh, 'correr';

12. O e o - Oráte, 'sangue';

13. P e p - Pahã, 'pau';

14. Ke k - Kalõ, 'cigano';

15. H e h - Haiáh, 'comer';

16. S e s - $\quad$ Sádo, 'parente';

17. Tet - Têbes, 'mesa';

18. U e u - Uráte, 'vermelho';

19. V e v - Váis, 'mão';

20. X e x - Xabuhõ, 'menino'; e

21. Z e z - Zêno, 'depois'. 
13. Chave de pronúncia

1. A, a para /a/;

2. B, b para $/ \mathrm{b} /$;

3. D, d para /d/;

4. E, e para /e/;

5. F, f para /f/;

6. G, g para /g/;

7. I, i para /i/;

8. J, j para /3/;

9. L, 1 para /1/;

10. M, m para $/ \mathrm{m} /$;

11. N, n para /n/;

12. O, o para /o/;

13. P, p para /p/; 
14. K, k para /k/;

15. H, h para $/ \mathrm{h} /$;

16. S, s para /s/;

17. T, t para /t/;

18. U, u para $/ \mathrm{u} /$;

19. V, v para /v/;

20. X, x para $/ \mathrm{S} /$; e

21. Z, z para /z/.

\section{Conclusão}

Este trabalho teve por objetivo a descrição pioneira na fonologia da língua kalõ, falada pelo Clã dos Cesteiros, no município de Arthur Nogueira, SP. Inicialmente, por ser tão-só uma descrição e documentação linguística, fez-se o mapeamento fonético do falar, bem como as várias rotas na diáspora cigana.

Depois, abordou-se o foco central do trabalho - a análise fonológica do idioma. Mapearam-se os sons consonantais e vocálicos; identificaram-se os padrões silábicos existentes; o acento da língua; a proposta gráfica; a condição para a inclusão dum arquifonema nasal; e outras análises supramencionadas.
A seguir, partiu-se à análise baseada em diversos descritivistas de línguas ágrafas, a fim de que os fatores fonológicos da língua fossem identificados e teorizados.

O falar estudado apresentou cinco vogais orais /a, e, i, o, u/; dezesseis consoantes /p, b, t, d, k, g, f, v, s, z, $\square, \square, \mathrm{h}$, m, n, l/; um par de semivogais /w/ e /j/; a ocorrência de Distribuição Complementar, e a não-constatação de Variantes Livres; a proposta dum arquifonema nasal em Coda silábica; a confecção do alfabeto da língua em caracteres latinos; seis Moldes Silábicos: V, VC, CV, CCV, CVC, CVCC ordenados de acordo com a ocorrência; bem como outros fatores analisados acima. 


\section{Bibliografía}

1. BARTH, F. Teorias da Etnicidade seguido de Grupos Étnicos e suas Fronteiras. São Paulo: Editora da Unesp, 1998.

2. CÂMARA Jr., J. M. Princípios de Lingüística Geral. Rio de Janeiro: Padrão, 1977.

3. CHOMSKY, N.; HALLE, M. The Sound Pattern of English. New York: Harper \& Row, 1968.

4. CLEMENTS, G. N.; KEYSER, S. J. A generative Theory of the Syllable. Cambridge: The MIT Press, 1983.

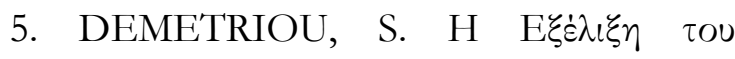

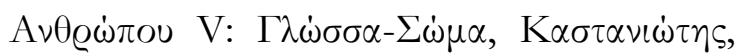
2000.

6. FEDERBUSH, S. לארשיב תירבעה וושלה םימעבו. Jerusalem: Mosad Harav Kook, 1967. 7. GOLDSMiTH, J. A. Autosegmental and Metrical Phonology. Cambridge: Blackwell, 1990.
8. International Phonetic Association. Handbook of the International Phonetic Association. Cambridge: Cambridge University Press, 1999.

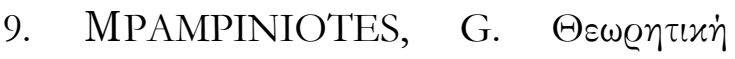

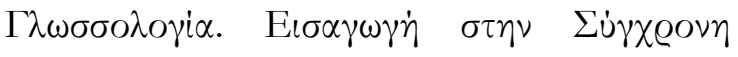
$\Gamma \lambda \omega \sigma \sigma o \lambda$ oүi $\alpha, 1980$.

10. NINYOLES, R. I. Idioma y poder social. Madrid: Editorial Tecnos, 1972.

11. ROSENTHAL, R. פיקמה גנלסה זולימ. Jerusalem: Keter, 2005.

12. STERN, N. Meaning and change of meaning. Hamburgo: Göteborg, 1931.

13. TROUBETZKOY, N. S. Grundzüge der phonologie. Paris, 1939.

14. TRUDGILL, P. Sociolinguistics: An introduction. London: Penguin, 1984.

15. WARDHAUGH, R. Languages in competition. Oxford: Blackwell, 1987. 